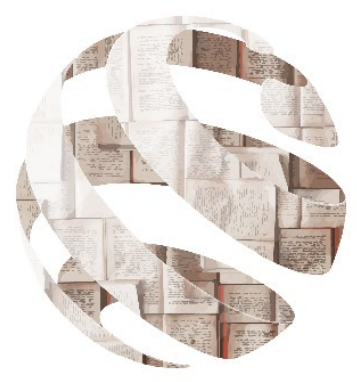

Adekoye, C. O. (2018). Reinterpreting 'Using Concept Maps in Law Schools to Foster Meaningful Learning: Evidence from a Pilot Study' (Deplano, 2018).

Journal of Learning and Teaching in Higher Education, 1 (2).

\title{
Creative writing
}

\section{Reinterpreting 'Using Concept Maps in Law Schools to Foster} Meaningful Learning: Evidence from a Pilot Study' (Deplano, 2018)

\section{Cecilia O. Adekoya ${ }^{1}$}

${ }^{1}$ coa10@student.le.ac.uk, English and Modern Languages, University of Leicester.

\begin{abstract}
For Rossana Deplano, learning goes beyond memorisation and her article wishes to provide an alternative that can help students shift from learning for tests to learning meaningfully. The article considers the method of using concept maps, which are similar to mind maps, but are formed as hierarchies, starting with the topic and expanding to various points. Rossana also believes that the road to meaningful learning needs the involvement of the teacher to help the students make connections between the prior and new knowledge. Taking all of this into consideration, the article inspired me to think about my own learning experience, and I reinterpreted the piece in the form of a poem, called 'Cycle'. It is loosely linked to Kolb's learning cycle, simplified as 'do, think, conclude, adapt'.
\end{abstract}

Keywords: Poetry, learning, disability, dyslexia, education, personal experience 


\section{Cycle}

Learning.

For what, exactly?

Can its purpose be more than grades,

Scores, titles?

Well, maybe. I suppose so.

One.

Let's start at the beginning.

The first book I read. What a world! Of fantasies, people,

Stories, new words.

Two.

I thought, 'How incredible to have discovered such a place of escape.'

Just by reading, I learnt to have an open mind,

As I met a spectrum of characters,

Some I loved and some I distanced.

Those words inspired conversations,

Speaking of what was to come, and hopes for happy endings

Four.

And so I went through schooling, my English teacher encouraging me with books to read,

And reminded me of stories before, making connections between the old and new

I discovered that words could express reality, a parallel of truth and fiction

Now here I am, a piece of paper in my hand, leaving this place with a degree

Three.

Learning is life and life is learning.

Explore your world. You might be surprised at what you find. Lift up your head, so clouded with study. There is meaning in every experience, it is right there waiting for you.

So, what are you learning? 